\title{
Spicy foods (chili peppers, ginger) in treatment of migraine headaches by Amos Gelbard.
}

\author{
Amos Gelbard \\ Zefat Academics Kibbutz Eilon, Galil Maaravi, Israel.
}

Keywords: Spicy food, Ginger, Chilli peppers, Capsaicin, Migraine, Headaches, Treatment.

Accepted on December 09, 2016

Migraine is a primary headache disorder characterized by recurrent headaches that are moderate to severe. Typically, the headaches affect one half of the head, are pulsating in nature, and last from two to $72 \mathrm{~h}$. Associated symptoms may include nausea, vomiting, and sensitivity to light, sound or smell.

Migraines are believed to be a neurovascular disorder with evidence supporting its mechanisms starting within the brain and then spreading to the blood vessels.

Hot spicy food is known to have a therapeutic effect in opening bodily pathways: in blood vessels (also known as a blood thinner) and in the respiratory system, and is known as an enhancer of tear shedding.

Several studies have shown Capsaicin, the active component in Chili peppers [1,2] and Ginger (Zingiber officinale) [3,4], to have a very positive effect in treatment of migraine headaches, both as a routine therapy and in treatment of ongoing headaches [1-4].

Its effect, as reported by patients, was decisively effective in comparison to those getting placebo treatments, in all of the referenced studies.
In compliance with the above mentioned knowledge on 'hot' spicy foods and the pathology of migraine headaches, it's safe to assume that such treatment, even just a dietary alteration towards eating more spicy foods, could be decisively effective as a preventive against migraine headaches, in those suffering from it, and in treatment of such headaches.

\section{References}

1. Fusco BM, Barzoi G, Agrò F. Repeated intranasal capsaicin applications to treat chronic migraine. Rome, Italy 2003.

2. Alexian M, Chatterjee A. Intranasal Capsaicin (IC) Rapidly relieves the pain of migraine and other severe headaches. NY/NJ, United States 2014.

3. Cady RK, Goldstein J, Nett R, et al. A double-blind placebocontrolled pilot study of sublingual feverfew and ginger (LipiGesicTMM) in the treatment of migraine 2011.

4. Mustafa T, Srivastava KC. Ginger (Zingiber officinale) in migraine headache. Institute of Biology, Odense University, Denmark 1990.

\section{*Correspondence to:}

Amos Gelbard

Zefat Academics Kibbutz Eilon

Galil Maaravi

Israel

Tel: 1-800-344-544

E-mail: amosgelbard@gmail.com 